\title{
Genetic Determination of Potential Trichoderma Species Using ISSR (Microsatellite) Marker in Uttar Pradesh, India
}

\author{
Mohammad Shahid, Mukesh Srivastava, Vipul Kumar*, Anuradha Singh and Sonika Pandey
}

Department of Plant Pathology, Biocontrol Laboratory, C. S. A. University of Agriculture \& Technology, India

\begin{abstract}
Seven Trichoderma sp. were collected from different locations of Uttar Pradesh, India for evaluating their bioefficiency by determining their genetic variations. PCR-based Inter Simple Sequence Regions (ISSR) Marker employing 6 primers produced 30 scorable bands out of which 27 bands were polymorphic. The Unweighted Pair Group Method of Arithmetic Means (UPGMA) dendrogram constructed from Nei's [14] genetic distance produced 2 main clusters ( 1 isolates in cluster 1 and 6 isolates in cluster 2 ). The result indicating their genetic diversity has opened new possibility of using the most efficient and more isolates of Trichoderma in the preparation of effective biopesticide.
\end{abstract}

Keywords: Genetic diversity; Trichoderma; ISSR

\section{Introduction}

Trichoderma is a soil fungus which reproduces asexually which is frequently isolated and most prevalently culturable. It is widely distributed in plant material, decaying vegetation, wood and other diverse habitats [1]. Trichoderma spp. are facultative anaerobes, grow saprophytically or as parasites on other Trichoderma and are able to grow in soils having a $\mathrm{pH}$ range of 2.5-9.5, although most of them prefer moderately acidic environment [2]. Most of the Trichoderma strains produce only asexual spores. However, a few strains have sexual stages which are not considered for biocontrol purposes. In recent past, morphological features were considered to determine different taxonomical aspects with the help of the asexual sporulation apparatus, but molecular approaches are now being used.

The strains show a high level of genetic diversity which can be used to produce various products of commercial and ecological interests. They are prolific producers of extra-cellular proteins, and also known to produce enzymes that degrade cellulose and chitin. Many other different strains produce more than 100 different metabolites having antibiotic activities. Since the introduction of biocontrol, Trichoderma species have been recognized as agents for the control of plant diseases and for their roles in increasing plant growth and development. The most useful strains show a property that is known as 'rhizosphere competence' that is, the ability to colonize and grow in association with plant roots. Much of the known biology and many of the uses of these fungi have been documented recently [3]. To isolate Trichoderma spp. different media are used. Some selective media such as Trichoderma specific media (TSM) are more efficient than others.

Depending on the species, Trichoderma can show no growth on Oat meal agar medium (OMA) and Rose Bengal Agar medium (RBA) etc., to broadly spreading growth on Potato Dextrose Agar media and Czapek's agar (Figure 1).

The Random Amplified Polymorphic DNA (ISSR) procedure developed by Williams et al. [4] and Welsh and McClelland [5] involves simultaneous amplification of several anonymous loci in the genome using primers of arbitrary sequence and has been used for genetic, taxonomic and ecological studies of several fungi including Trichoderma [6,7]. The ability to reliably distinguish members of different species, fingerprint of different genotypes and an estimate of the amount of variation within a species is useful for a breeding program. ISSR is a molecular technique used for such purposes. ISSR technique is easy and inexpensive. The advantages of the ISSRs are the requirement for small amount of DNA (5-20 ng), single short (9 to $10 \mathrm{bp}$ ) primers of arbitrary sequence, and the rapidity to screen for polymorphisms, the efficiency to generate a large number of markers for genomic mapping and the potential automation of the technique. In addition, no prior knowledge of sequence is required [8]. Since primers can be chosen arbitrarily, any organism can be mapped with the same set of primers but there is some loss of information because ISSR markers are dominant rather than co-dominant. If one of the alleles at an ISSR site is unamplifiable, then marker homozygote cannot be distinguished from marker/null heterozygote. Other problems arise if products of different loci have similar molecular weights and so will be indistinguishable on a gel because of comigration. The problem of uncertain homology becomes serious at higher taxonomic levels where it is likely that only a few shared bands are generated. Though ISSR has some limitations, but it is being used as one of the powerful techniques for genetic studies, for example, analysis of genetic variation in plants, fungi and bacteria [9] and construction of the first linkage maps for certain plant species and pathogens [10].

IPM Lab biopesticide (code- 34/USDA/BG-ARS122) formulated out of Trichoderma is in commercial use [11]. The strain Trichoderma harzianum $\mathrm{CP}$ was used in the formulation. A total of 46 isolates were collected from different regions of Uttar Pradesh. Based on growth rate and sporulation capacity, the strain T. harzianum $\mathrm{CP}$ was selected and used in the formulation [12]. Physiological variations of the isolates were studied earlier but not in details. Variation at molecular level has not been studied.

Molecular study may reveal any variation that exists among the isolates in support of the variation in physiological properties. It is well

*Corresponding author: Mohammad Shahid, Department of Plant Pathology Biocontrol Laboratory, C. S. A. University of Agriculture \& Technology, Kanpur-208002, India, Tel: 0512253 4156; E-mail: shahid.biotech@rediffmail.com

Received February 17, 2014; Accepted April 10, 2014; Published April 16, 2014

Citation: Shahid M, Srivastava M, Kumar V, Singh A, Pandey S (2014) Genetic Determination of Potential Trichoderma Species Using ISSR (Microsatellite) Marker in Uttar Pradesh, India. J Microb Biochem Technol 6: 174-178. doi:10.4172/19485948.1000139

Copyright: @ 2014 Shahid M, et al. This is an open-access article distributed under the terms of the Creative Commons Attribution License, which permits unrestricted use, distribution, and reproduction in any medium, provided the original author and source are credited 
Citation: Shahid M, Srivastava M, Kumar V, Singh A, Pandey S (2014) Genetic Determination of Potential Trichoderma Species Using ISSR (Microsatellite) Marker in Uttar Pradesh, India. J Microb Biochem Technol 6: 174-178. doi:10.4172/1948-5948.1000139

established that previous knowledge about the genetic relationships among breeding materials is crucial for the efficient use of the germplasm in a breeding program [13]. In Uttar Pradesh, research findings on genetic analysis of different Trichoderma isolates are not available. Although no specific markers were found to discriminate different isolates effectively, the ISSR technique revealed some degree of polymorphisms for variation study of different Trichoderma isolates and the results obtained from the experiment using ISSR markers have been presented and expressed in tables and figures for ease of understanding. More isolates of Trichoderma have been recently collected. The present research work was undertaken to determine genetic variations among some isolates of Trichoderma spp. using ISSR technique for evaluating their efficiency as biopesticides.

\section{Materials and Methods}

An in vitro experiment was conducted at the Biocontrol Laboratory, Department of Plant Pathology, C. S. Azad University of Agriculture and Technology, Kanpur Uttar Pradesh. Thirty five Trichoderma isolates collected from diverse origin of different hosts and locations in Uttar Pradesh were used in the present experiment (Table 1).

\section{Genomic DNA isolation}

Seven strains of Trichoderma spp. were used for the ISSR. Genomic DNA extraction from Trichoderma isolates Isolation of fungal genomic DNA was done by growing the fungi for 3-4 days. The mycelia were incubated with lysis buffer containing $250 \mathrm{mM}$ Tris $-\mathrm{HCl}$ ( $\mathrm{pH} \mathrm{8.0}$ ), $50 \mathrm{mM}$ EDTA (pH8. 0), $100 \mathrm{mM} \mathrm{NaCl}$ and $2 \%$ SDS, for $1 \mathrm{hr}$ at $60^{\circ} \mathrm{C}$ followed by centrifugation at $12,000 \mathrm{rpm}$ for $15 \mathrm{~min}$. The supernatant was then extracted with equal volume of water saturated phenol and further centrifuged at $12,000 \mathrm{rpm}$ for $10 \mathrm{~min}$; the aqueous phase was further extracted with equal volume of phenol: chloroform: isoamyl alcohol (25:24:1) and centrifuge at 12,000 rpm for $15 \mathrm{~min}$; the aqueous phase was then transferred in a fresh tube and the DNA was precipitated with chilled ethanol (100\%). DNA was pelleted by centrifuging at $12000 \mathrm{rpm}$ for $15 \mathrm{~min}$ and washed in $70 \%$ ethanol by centrifugation. The pellets were air dried and suspended in TE buffer (Tris EDTA buffer) (pH 8.0).

\section{Qualitative and quantitative estimation of DNA}

The extraction of total genomic DNA from the Trichoderma isolates as per the above procedure was followed by RNAase treatment. Genomic DNA was re suspended in $100 \mu \mathrm{l} 1 \mathrm{X}$ TE buffer and incubated at $37^{\circ} \mathrm{C}$ for $30 \mathrm{~min}$ with RNAse $(60 \mu \mathrm{g})$. After incubation the sample was re extracted with PCI (Phenol: Chloroform: Isoamylalcohol 25:24:1) solution and RNA free DNA was precipitated with chilled ethanol as described earlier. The quality and quantity of DNA was analyzed both All isolates of Trichoderma were taken up for PCR spectrophotometrically and in $0.8 \%$ agarose gel. The DNA from all isolates produced clear sharp bands, indicating good quality of DNA.

\section{PCR amplification of its region of Trichoderma species}

Amplification Genomic DNA was amplified by mixing the template DNA (50 ng), with the polymerase reaction buffer, dNTP mix, primers and Taq polymerase. Polymerase Chain Reaction was performed in a total volume of $100 \mu \mathrm{l}$, containing $78 \mu \mathrm{l}$ deionized water, $10 \mu \mathrm{l} 10 \mathrm{X}$ Taq pol buffer, $1 \mu \mathrm{l}$ of $1 \mathrm{U}$ Taq polymerase enzyme, $6 \mu \mathrm{l} 2$ mMdNTPs, $1.5 \mu \mathrm{l}$ of $100 \mathrm{mM}$ reverse and forward primers and $1 \mu \mathrm{l}$ of 50 ng template DNA. PCR was programmed with an initial denaturing at $94^{\circ} \mathrm{C}$ for $5 \mathrm{~min}$. followed by 30 cycles of denaturation at $94^{\circ} \mathrm{C}$ for 30 sec, annealing at $59^{\circ} \mathrm{C}$ for $30 \mathrm{sec}$ and extension at $70^{\circ} \mathrm{C}$ for $2 \mathrm{~min}$ and the final extension at $72^{\circ} \mathrm{C}$ for $7 \mathrm{~min}$ ina Primus 96 advanced gradient Thermocycler. PCR product $(20 \mu \mathrm{l})$ was mixed with loading buffer $(8$ $\mu 1$ ) containing $0.25 \%$ bromophenol blue, $40 \% \mathrm{w} / \mathrm{v}$ sucrose in water and then loaded in $2 \%$ Agarose gel with $0.1 \%$ ethidium bromide for examination with horizontal electrophoresis.

\section{Banding analyses}

Since ISSR markers are dominant, we assumed that each band represented the phenotype at a single allelic locus [4]. One molecular weight marker, 100 base pair DNA ladder was used to estimate the size of the amplification products by comparing the distance traveled by each fragment with that of the known sized fragments of molecular weight markers. All distinct bands or fragments (ISSR markers) were thereby given identical numbers according to their position on gel and scored visually on the basis of their presence (I) or absence (0), separately for each individual and each primer. Bands which were not identified considered as non-scorable.

\section{Dendrogram construction}

The scores obtained using all primers in the ISSR analysis were
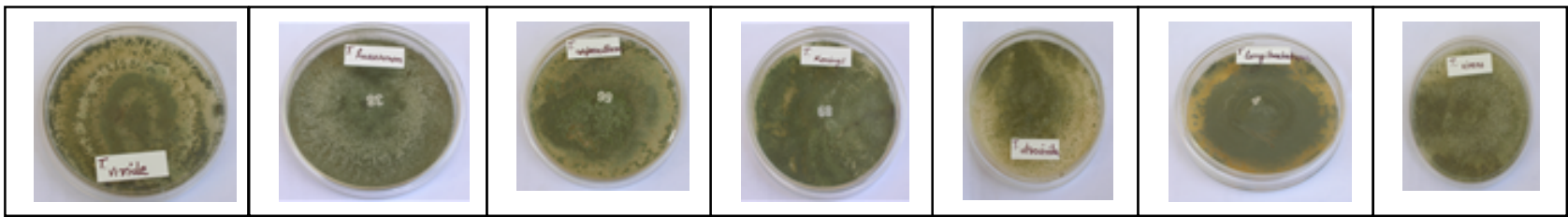

Figure 1: Morphological descriptors used for characterization of native isolates of Trichoderma sp.

\begin{tabular}{|c|c|c|c|c|c|c|}
\hline Strain No. & Name of Bio-agent & Strain code & ITCC Acc. No & NBAIM Acc. No. & Gen bank NCBI No. & Source \\
\hline T1 & T. viride & 01PP & 8315 & $F-03110$ & JX119211 & Hardoi \\
\hline T2 & T. harzianum & Th azad & 6796 & F-03109 & KC800922 & CSA Kanpur Nagar \\
\hline T3 & T. asperellum & Tasp/CSAU & 8940 & $F-03108$ & KC800921 & CSA Kanpur Nagar \\
\hline T4 & T. koningii & TK (CSAU) & 5201 & $F-03112$ & KC800923 & CSA Kanpur Nagar \\
\hline T5 & T. atroviride & $71 \mathrm{~L}$ & 7445 & F-03107 & KC 008065 & Hardoi \\
\hline T6 & T. longibrachiatum & $21 \mathrm{PP}$ & 7437 & F-03111 & JX978542 & Kaushambi \\
\hline $\mathrm{T} 7$ & T. virens & T.vi (CSAU) & 4177 & F-03106 & KC800924 & CSA Kanpur Nagar \\
\hline
\end{tabular}

Table 1: Cultural description of seven potential and effective species of Trichoderma. 
Citation: Shahid M, Srivastava M, Kumar V, Singh A, Pandey S (2014) Genetic Determination of Potential Trichoderma Species Using ISSR (Microsatellite) Marker in Uttar Pradesh, India. J Microb Biochem Technol 6: 174-178. doi:10.4172/1948-5948.1000139

pooled to create -a single data matrix. This was used to estimate polymorphic loci, [14] gene diversity, population differentiation (Gst), gene flow $(\mathrm{Nm})$, genetic distance (D) and to construct a UPGMA (Unweighted Pair Group Method of Arithmetic Means) dendrogram among populations using a computer program, POPGENE (Version I. 31). The same program was also used to perform test of homogeneity in different loci between population pairs. Gene frequency estimation for ISSR loci was based on the assumption of a two-allele system. Only one of the two alleles is capable to amplify an ISSR marker by primer annealing, at an unknown genomic position (locus). The other is the "null" allele incapable of amplification, mainly because of loss of primer annealing site by mutation. The two-allele assumption is in most cases acceptable because, dominant loci showing band shifts are few. In this system only a null homozygote is detectable as negative for the ISSR - band of interest. Under the assumption of Hardy-Weinberg equilibrium, the null allele frequency $(\mathrm{q})$ may be $(\mathrm{N} / \mathrm{n}) \mathrm{1} / 2$, where $\mathrm{N}$ and $\mathrm{n}$ are the number of band negative individuals observed and the sample size, respectively. The frequency of the other allele $(\mathrm{P})$ is 1 -q. The assumption of the two-allele system enables us to calculate the Nei's, genetic distance [14] from the ISSR pattern. Nei's genetic distance and identity values were computed from frequencies of polymorphic markers to estimate genetic relationship between the studied thirty five Trichoderma isolates using the unweighted pair-group method of arithmetic means (UPGMA). The dendrogram was then constructed using the POPGENE (Version1. 31) computer program.

\section{Results and Discussion}

The stated experiment was undertaken to determine genetic variation among some isolates of Trichoderma spp. using ISSR analysis. The results are presented here.

\section{ISSR analyses}

Primer selection and ISSR pattern: Six primers were initially screened for their ability to produce polymorphic patterns among 7 strains of Trichoderma spp. and six primers viz., A1, A2, A3, A4, A5 and A6 which showed comparatively maximum number of high resolution bands and distinct polymorphic amplified products were selected. Selected three primers (A2, A3 and A5) generated 100\% polymorphic bands, i. e. there were no monomorphic bands. The five different primers generated various banding patterns, ranging from 6 (A1), 4 (A2), 4 (A3), 6 (A4), 3 (A5) and 7 (A6). The primer A6 produced the highest numbers of polymorphic bands (7). Thus it showed a higher level of polymorphism. On the other hand, the primer A5 generated least number of polymorphic bands (3).

The DNA polymorphisms were detected according to presence or absence of bands (Figures 2-7). Absence of bands may be caused by failure of primers to anneal a site in some individuals due to nucleotide sequence differences or by insertions or deletions between primer sites [15] as shown in the Tables 2 and 3.

\section{Dendrogram}

Dendrogram based on Nei's [14] genetic distance using Unweighted Pair Group Method of Arithmetic Means (UPGMA) indicated segregation of the 7 isolates of Trichoderma spp. into two main clusters: T3 On the other hand T1, T2, T4, T5, T6, T7 were grouped in cluster 2, (Figure 1). Cluster2 was again divided into two sub-clusters. Subcluster 1 has isolate-T2 and isolates T1, T4, T5, T6 and T7 belonged to subcluster 2. Sub-cluster 2 was again divided into two sub sub-cluster. Sub sub-cluster 2 was dark green color. Sub sub-cluster 1 was then divided into two groups. Group 1 has isolates green, yellowish green color and rest was in group 2. Group 2 was divided into two sub groups which were dark green and green. Further, the isolates of cluster2 were

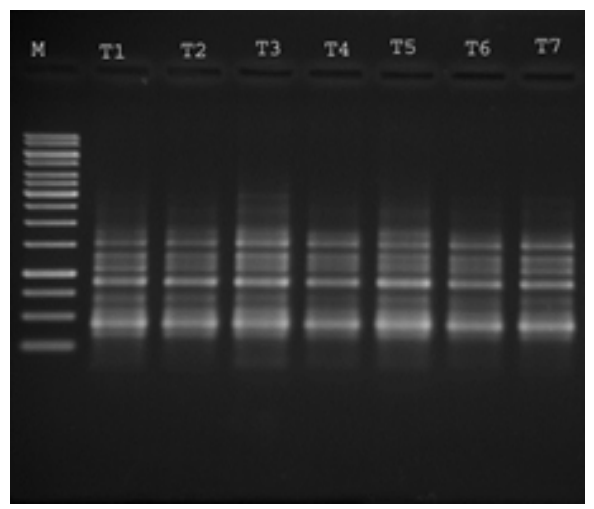

Figure 2: PCR amplification of ISSR (A1 marker) of Trichoderma species (Lane 1-7) Lane M: Low range DNA Marker, Lane 1- ITCC-8315/01PP, Lane2ITCC-6796/Th azad, Lane3- ITCC-8940/Tasp/CSAU, Lane4- ITCC-5201/TK (CSAU), Lane5- ITCC-7445/71 L, Lane6- ITCC-7437/21 PP, Lane7- ITCC4177/T.vi (CSAU)

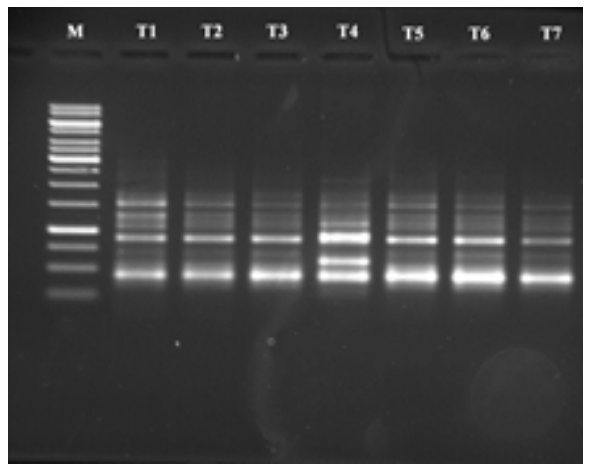

Figure 3: PCR amplification of ISSR (A2 marker) of Trichoderma species (Lane 1-7) Lane M: Low range DNA Marker, Lane 1- ITCC-8315/01PP, Lane2ITCC-6796/Th azad, Lane3- ITCC-8940/Tasp/CSAU, Lane4- ITCC-5201/TK (CSAU), Lane5- ITCC-7445/71 L, Lane6- ITCC-7437/21 PP, Lane7- ITCC4177/T.vi (CSAU)

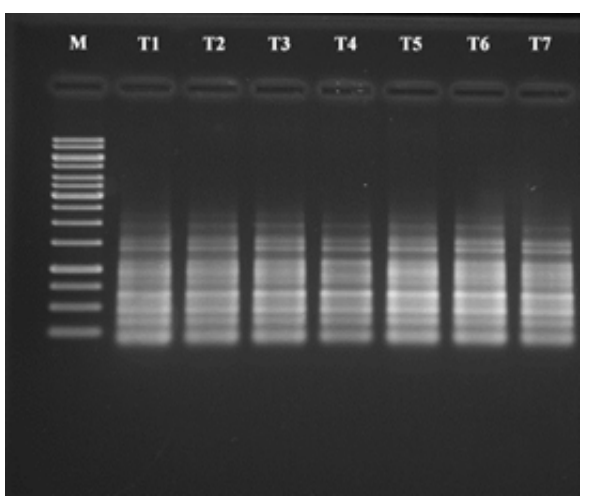

Figure 4: PCR amplification of ISSR (A3 marker) of Trichoderma species (Lane 1-7) Lane M: Low range DNA Marker, Lane 1- ITCC-8315/01PP, Lane2ITCC-6796/Th azad, Lane3- ITCC-8940/Tasp/CSAU, Lane4- ITCC-5201/TK (CSAU), Lane5- ITCC-7445/71 L, Lane6- ITCC-7437/21 PP, Lane7- ITCC4177/T.vi (CSAU) 
Citation: Shahid M, Srivastava M, Kumar V, Singh A, Pandey S (2014) Genetic Determination of Potential Trichoderma Species Using ISSR (Microsatellite) Marker in Uttar Pradesh, India. J Microb Biochem Technol 6: 174-178. doi:10.4172/1948-5948.1000139

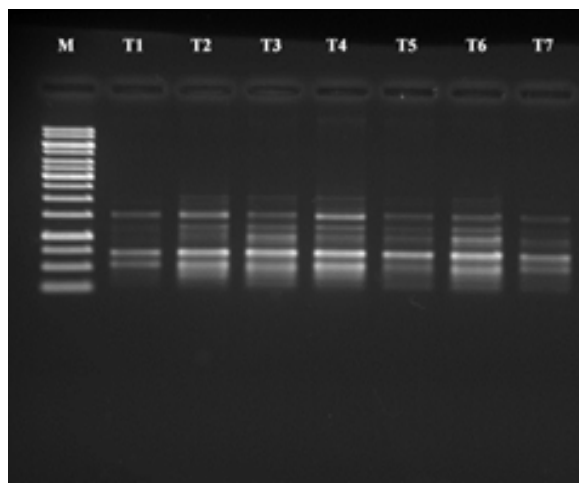

Figure 5: PCR amplification of ISSR (A4 marker) of Trichoderma species (Lane 1-7) Lane M: Low range DNA Marker, Lane 1- ITCC-8315/01PP, Lane2ITCC-6796/Th azad, Lane3- ITCC-8940/Tasp/CSAU, Lane 4- ITCC-5201/TK (CSAU), Lane5- ITCC-7445/71 L, Lane6- ITCC-7437/21 PP, Lane7- ITCC4177/T.vi (CSAU).

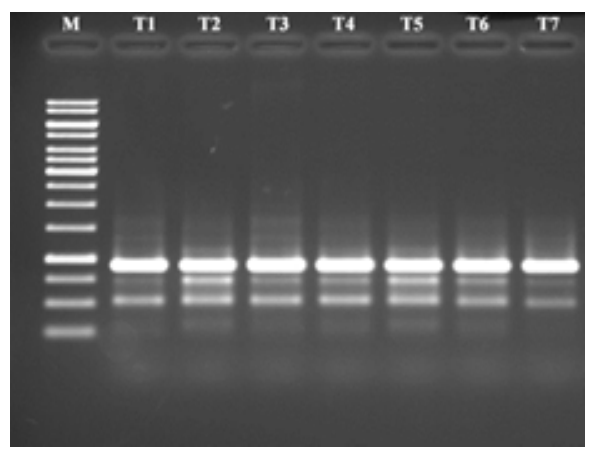

Figure 6: PCR amplification of ISSR (A5 marker) of Trichoderma species (Lane 1-7) Lane M: Low range DNA Marker, Lane 1- ITCC-8315/01PP, Lane2ITCC-6796/Th azad, Lane3- ITCC-8940/Tasp/CSAU, Lane4-ITCC-5201/TK (CSAU), Lane5- ITCC-7445/71 L, Lane6- ITCC-7437/21 PP, Lane7- ITCC4177/T.vi (CSAU).

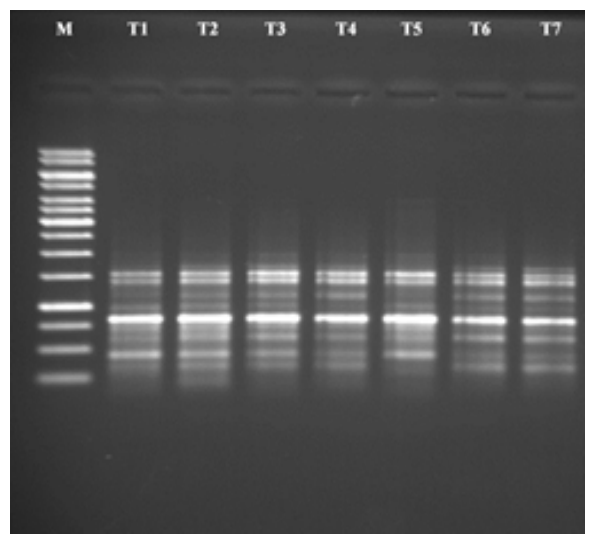

Figure 7: PCR amplification of ISSR (A6 marker) of Trichoderma species (Lane 1-7) Lane M: Low range DNA Marker, Lane 1- ITCC-8315/01PP, Lane2ITCC-6796/Th azad, Lane3- ITCC-8940/Tasp/CSAU, Lane4-ITCC-5201/TK (CSAU), Lane5- ITCC-7445/71 L, Lane6- ITCC-7437/21 PP, Lane7- ITCC4177/T.vi (CSAU).

divided into two sub-clusters, sub-cluster 2 contained T4, T6, in which $\mathrm{T} 5, \mathrm{~T} 1$ and $\mathrm{T} 7$ were light green.
The primers ISSR-A6 and ISSR-A1 produced maximum number of bands (7 and 6), whereas ISSR-A5 generated the least number (3). The six primers generated 30 total numbers of bands and average 27 scorable bands where all were polymorphic bands per primer, hence the percentage of polymorphism was $90 \%$ and the percentage of monomorphism is $10 \%$. Thus, this preliminary studies indicates that the Trichoderma spp. isolates under studies had very good diversity and there are strong possibility to get the isolates specific primers that will utilized for identify the particular Trichoderma isolates -specific primers that will be utilized for identifying the particular Trichoderma isolates with good biological potential from the field isolates without going the cumbersome bioassay. Strong and weak bands were produced in the ISSR reactions which is a well-known and widely used marker throughout the world. Weak bands resulted from low homology between the primer and the pairing site on the DNA strand [16]. Fujimori and Okuda [17] examined 74 strains of Trichoderma by ISSR profiles and the results were consistent with the morphological, physiological and ecological data of these strains which agree the present study. Schlick et al. [18] and Zimand et al [19] used ISSR markers obtained from arbitrary primers to distinguish strains of Trichoderma. This report agrees the findings of the present investigation.

Molecular characterization of different Trichoderma isolates is not available and there were no specific markers to differentiate the isolates

\begin{tabular}{|l|l|l|l|l|}
\hline Primer Name & Sequence( 5'-3') & Mer & TM & \% GC \\
\hline ISSR primers & & & & \\
\hline A-1 & 5'YC (TG)7T3' & 17 & 49.77 & 47 \\
\hline A-2 & 5'(GA)9AC3' & 20 & 53.70 & 55 \\
\hline A-3 & 5'(GA)9T3' & 20 & 58.01 & 47 \\
\hline A-4 & 5'(GA)8AC3' & 18 & 56.35 & 40 \\
\hline A-5 & 5'(AG)8AC3' & 18 & 60.17 & 50 \\
\hline A-6 & 5'(AG)8AT3' & 18 & 60.26 & 47 \\
\hline
\end{tabular}

Table 2: The nucleotide sequence used for ITS and Trichoderma ISSR primers.

\begin{tabular}{|l|l|l|l|l|}
\hline SI. No. & Primers & Total loci & Polymorphic loci & Polymorphic \% age \\
\hline A-1 & 5'YC (TG)7T3' $^{\prime}$ & 6 & 5 & 83 \\
\hline A -2 & 5'(GA)9AC3' $^{\prime}$ & 4 & 4 & 100 \\
\hline A-3 & 5'(GA)9T3' $^{\prime}$ & 4 & 4 & 100 \\
\hline A-4 & 5'(GA)8AC3' $^{\prime}(6$ & 5 & 83 \\
\hline A-5 & 5'(AG)8AC3' $^{\prime}$ (AG) & 3 & 3 & 100 \\
\hline A-6 & 5'(AG)8AT3' & 7 & 6 & 85 \\
\hline & & 30 & 27 & 90 \\
\hline
\end{tabular}

Table 3: Analysis of the polymorphism obtained with ISSR markers in 7 Trichoderma sp.

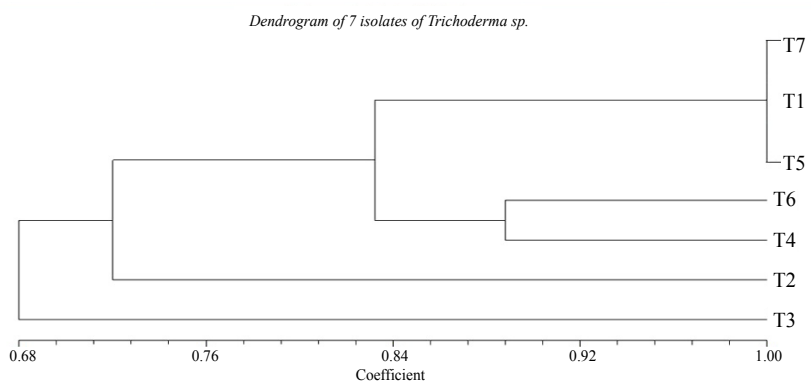

Figure 8: Dendrogram for Trichoderma spp. isolates as revealed by ISSR markers. Where: 1: Th Azad, 2: $71 \mathrm{~L}, 3:$ 21PP, 4: TK/CSAU, 5: Tasp/CSAU, 6: $T$. virens CSAU, 7: 01PP. 
Citation: Shahid M, Srivastava M, Kumar V, Singh A, Pandey S (2014) Genetic Determination of Potential Trichoderma Species Using ISSR (Microsatellite) Marker in Uttar Pradesh, India. J Microb Biochem Technol 6: 174-178. doi:10.4172/1948-5948.1000139

effectively. The ISSR technique revealed some degree of polymorphisms for variation study of thirty five Trichoderma isolates in the present study and the results obtained from the experiment showed significant molecular variation among the isolates in relation to morphological characters. Therefore, findings of the present investigation agree with the report of Kullnig et al. [20] who recognized about 35 Trichoderma species on the basis of morphological and molecular characters and revealed genetic variability among the isolates through ISSR analysis. Hadrys et al. [21] have provided relatively simple and inexpensive method for examining variation in the total genome through ISSR-PCR technique. On the other hand Peteira et al. [22] and Shahid et al. [23] presented the genetic diversity among Trichoderma isolates by ISSR technique which also supports the results of the present investigation (Figure 8).

\section{Conclusion}

Six ISSR primers were used for testing the percentage of polymorphism. More than $90 \%$ Genetic diversity was found among the isolates. This shows that there is complete variability within the isolates of Trichoderma species isolated from different fields of $\mathrm{U}$. P. Preliminary studies indicate that the Trichoderma species isolates under studies have very good diversity and there is strong possibility to get the isolates specific primers that will be utilized for identify the particular Trichoderma isolates with good biological potential form the field isolates without going the cumbersome bio assay.

\section{Acknowledgement}

The authors are grateful for the financial support granted by the Indian Council of Agriculture Research (ICAR) Govt. of India under the Niche Area of Excellence on "Exploration and Exploitation of Trichoderma as an antagonist against soil borne pathogens" running in the Bio-control Laboratory, Department of Plant Pathology, C. S. A. University of Agriculture and Technology, Kanpur, Uttar Pradesh, India.

\section{References}

1. Ranasingh N (2006) Working in the Regional Centre of Central Tuber Crops Research Institute, Dumduma, Bhubaneswar -751019.

2. Grondona I, Hermosa M (1997) Physiological and biochemical characterization of Trichoderma harzianum, a biological control agent against soilborne fungal plant pathogens. Appl Environ Microbiol 63: 3189-3198.

3. Harman GE (2000) The myths and dogmas of biocontrol: changes in perceptions derived from research on Trichoderma harzianum strain T-22. Plant Disease 84: 377-393.

4. Williams JG, Kubelik AR, Livak KJ, Rafalski JA, Tingey SV (1990) DNA polymorphisms amplified by arbitrary primers are useful as genetic markers. Nucleic Acids Res 18: 6531-6535.

5. Welsh J, McClelland M (1990) Fingerprinting genomes using PCR with arbitrary primers. Nucleic Acids Res 18: 7213-7218.

6. Abbasi PA, Miller SA, Meulia T, Hoitink HA, Kim JM (1999) Precise detection and tracing of Trichoderma hamatum 382 in compost-amended potting mixes by using molecular markers. Appl Environ Microbiol 65: 5421-5426.

7. Paavanem- Huhtala S, Avikainem H, Ylimattila T (2000) Development of strain specific primers for a strain of Gliocladium catenulatum used in biological control. 106: 187-198.

8. Sobral BW, Honeycutt RJ (1993) High output genetic mapping of polyploids using PCR-generated markers. Theor Appl Genet 86: 105-112.
9. Mailer RJ, Scarth R, Fristensky B (1994) Discrimination among cultivars of rapeseed (Brassica napus L.) using DNA polymorphisms amplified from arbitrary primers. Theor Appl Genet 87: 697-704.

10. Yang X, Quiros CF (1995) Construction of a genetic linkage map in celery using DNA-based markers. Genome 38: 36-44.

11. Meah MB, Islam MM (2005) Development of an integrated approach for management of Phomopsis blight and fruit rot of eggplant in Bangladesh. Annual research report (2004-2005). Department of Plant Pathology, Bangladesh Agricultural University, Mymensingh, Bangladesh. p. 42.

12. Meah MB (2007) Formulation of Bio-pesticide in controlling Phomopsis fruit rot, foot/collar rot and shoot and fruit borer of eggplant annual research Report (2006-2007), USDA-Bangladesh Collaborative Research. p.4-11

13. Nienhuis J, Tivang J, Skroch P (1994) Analysis of genetic relationships among genotypes based on molecular markers data.

14. Nei M (1972) Genetic distance between populations. American Naturalist 106 283-292.

15. Clark AG, Lanigan CM (1993) Prospects for estimating nucleotide divergence with RAPDs. Mol Biol Evol 10: 1096-1111.

16. Thormann CE, Ferreira ME, Camargo LE, Tivang JG, Osborn TC (1994) Comparison of RFLP and RAPD markers to estimating genetic relationships within and among cruciferous species. Theor Appl Genet 88: 973-980.

17. Fujimori $F$, Okuda $T$ (1993) Application of the random amplified polymorphic DNA using the polymerase chain reaction for efficient elimination of duplicate strains in microbial screening. I. Fungi. J Antibiot (Tokyo) 47: 173-182.

18. Schlick A, Kuhls K, Meyer W, Lieckfeldt E, Börner T, et al. (1994) Fingerprinting reveals gamma-ray induced mutations in fungal DNA: implications fo identification of patent strains of Trichoderma harzianum. Curr Genet 26: 74-78.

19. Zimand G, Valinsky L, Elad Y, Chet I, Manulis S (1994) Use of the RAPD procedure for the identification of Trichoderma strains. Mycological Research 98: $531-534$

20. Kullnig C, Szakacs G, Kubicek CP (2000) Molecular identification of Trichoderma species from Russia, Siberia and the Himalaya. Mycological Research 104: 1117-1125.

21. Hadrys H, Balick M, Schierwater B (1992) Applications of random amplified polymorphic DNA (RAPD) in molecular ecology. Mol Ecol 1: 55-63.

22. Peteira B, Martinez B, Muniz Y, Miranda I (2001) Molecular characterization of the genetic diversity of some promising isolates of Trichoderma spp. by RAPD. Revista-de-Proteccion-Vegetal 16: 157-158.

23. Shahid M, Singh A, Srivastava M, Srivastava DK (2014) Molecula Characterization of Trichodermaviride Isolated from Rhizospheric Soils of Uttar Pradesh Based on rDNA Markers and Analysis of Their PCR-ISSR Profiles. J Mol Biomark Diagn 5: 169 